\title{
Influence of Defects on Low Temperature Diffusion of Boron in SiC
}

\author{
Ilkham G. Atabaev ${ }^{1}$, Tojiddin M. Saliev ${ }^{1}$, Dilmurad Saidov ${ }^{1}$, Vadim A. Pak ${ }^{1}$, Khimmatali Juraev ${ }^{1}$, \\ Chin-Che Tin ${ }^{2}$, Bakhtiyar G. Atabaev ${ }^{3}$, Vyacheslav N. Giryansky ${ }^{3}$ \\ ${ }^{1}$ Physical Technical Institute of Uzbek Academy of Sciences, Tashkent, Uzbekistan; ${ }^{2}$ Department of Physics, Auburn University, \\ Alabama, USA; ${ }^{3}$ Arifov Institute of Electronics, Uzbek Academy of Sciences, Tashkent, Uzbekistan. \\ Email: atvi@uzsci.net, cctin@physics.auburn.edu,
}

Received January $18^{\text {th }}$, 2011; revised March $17^{\text {th }}$, 2011; accepted May 30 ${ }^{\text {th }}, 2011$.

\begin{abstract}
The low temperature diffusion of Boron in bulk SiC crystals is investigated and simplified model of such diffusion is presented. The method of UV stimulated etching by aqueous solution of $\mathrm{KOH}$ is proposed and some experimental data on influence of defects on quality of prepared $p$ - $n$ junctions are presented.
\end{abstract}

Keywords: Diffusion, Activation Energy, Silicone Carbide, Annealing, Vacancy

\section{Introduction}

Due to its unique material properties, silicon carbide (SiC) is very prospective material for fabrication of high power, high temperature electronic devices that can operate in harsh environment. One of the constraining factors in the fabrication of silicon carbide devices is the necessity of using high temperature of about $1800^{\circ} \mathrm{C}-2200^{\circ} \mathrm{C}$ to introduce impurity by thermal diffusion. Due to the relatively low melting temperature of silicon $\left(1412^{\circ} \mathrm{C}\right)$, conventional high temperature diffusion of shallow impurities in $\mathrm{SiC}$ epilayers grown on $\mathrm{Si}$ is impossible. In the case of doping by ion implantation, a post-implantation dopant activation annealing at $\sim 1600^{\circ} \mathrm{C}$ is needed. Hightemperature thermal processing can cause surface deterioration resulting in poor device characteristics. Therefore, a reduction in processing temperature for impurity introduction in $\mathrm{SiC}$ is important.

To reduction of temperature of diffusion of impurity in $\mathrm{SiC}$ up to $1250^{\circ} \mathrm{C}-1300^{\circ} \mathrm{C}$ we are proposed and investigated new method of low-temperature diffusion of boron [1-4]. In this method, on surface of SiC crystal creates a layer of borosilicate glass, then sample annealed in air. As we have expected, in these conditions, there is the flow of carbon vacancies, which allows to reduce the temperature of diffusion. Experiments have shown that the temperature of diffusion decreased to $1150^{\circ} \mathrm{C}$ $1250^{\circ} \mathrm{C}$. Boron concentration reached a high value to the $10^{20-21} \mathrm{~cm}^{-3}$.
Although this technique has been demonstrated to be applicable to the fabrication of SiC devices [4], further work needs to be done to optimize the technique in order to improve the surface morphology and reduce crystalline defects and to improve p-n junction characteristics.

To achieve these goals, further research of mechanism of low-temperature diffusion of boron is necessary. As mentioned above, we have assumed that on the surface of $\mathrm{SiC}$ crystal a flow of carbon vacancies creates. In this case, the diffusion area is saturated by carbon vacancies and the reducing of diffusion temperature related with interaction of impurity with $V_{\mathrm{C}}$. However, it seen from experiments, a significant part of Boron atoms after diffusion was in the electrically active state in the silicon sublattice of $\mathrm{SiC}$. It means that during the diffusion concentration of $V_{\mathrm{Si}}$ vacancies should be large. Concentration of Boron was also very high! Thus the need to find out-how occurs the large concentration of silicon vacancies during low-temperature diffusion.

In the defect enhanced diffusion the method of processing the crystal surface is very important. It is always important, but in our case, diffusion is stimulated by defects $\left(V_{\mathrm{C}}, V_{\mathrm{Si}}, V_{\mathrm{SiC}}\right)$ that interact with structural defects. So, the quality of the crystal surface in our method has played a key role. That is why it is necessary to conduct our research together with the study of etching of the crystal.

In a previous article [4] the results of research carried out on $\mathrm{SiC} / \mathrm{Si}$ and $\mathrm{SiC} / \mathrm{SiC}$ structures were presented. In 
this paper, we report on the simplified model of lowtemperature diffusion of impurity in bulk SiC crystals, some experimental data on etching and influence of surface morphology on IV characteristics are presented.

\section{Experimental Results and Discussion}

\subsection{Physical Approaches for the Implementation of Low-Temperature Diffusion}

It is well known that mobile point defects play an important role in diffusion processes in semiconductors. And to reduce the temperature of diffusion the increased concentration of mobile point defects can be used. One of the possible ways of introducing point defects in crystal is the irradiation of samples during diffusion process.

In [5] described the results of studies of radiationstimulated diffusion of boron in silicon and silicon carbide irradiated with protons. It is shown that in silicon the temperature of diffusion falls, however, in silicon carbide does not. As shown in [5] a significant decrease in temperature diffusion of cesium (up to temperatures of $1150^{\circ} \mathrm{C}-1300^{\circ} \mathrm{C}$ ) occurs when the amorphization of $\mathrm{SiC}$ samples. Of course, this path can not be regarded as optimal for the manufacturing technology of semiconductor devices.

On our opinion, the surface oxidation of silicon carbide is a next possible way to effective introduction of point defects (vacancies) in the crystal. Our method of diffusion [1-4] was a modification of the surface oxidation. We then assumed that the crystal surface of silicon carbide is formed vacancy flux of carbon. However, we recently found a great article of S. C. Singhal on oxidation kinetics of silicon carbide [6].

In this work [6] is described that at temperatures $1100^{\circ} \mathrm{C}-1400^{\circ} \mathrm{C} \mathrm{SiC}$ exhibits two types of oxidation behavior, "active" and "passive", depending upon the ambient oxygen potential. At high oxygen pressures, "passive" oxidation occurs wherein a protective film of $\mathrm{SiO}_{2}(\mathrm{~s})$ is formed on the surface by the reaction:

$$
2 \mathrm{SiC}(\mathrm{s})+3 \mathrm{O}_{2}(\mathrm{~g}) \rightarrow 2 \mathrm{SiO}_{2}(\mathrm{~s})+2 \mathrm{CO}(\mathrm{g})
$$

At low oxygen potentials, severe "active” oxidation occurs due to the formation of gaseous products according to reactions:

$$
\begin{gathered}
\mathrm{SiC}(\mathrm{s})+2 \mathrm{SiO}_{2}(\mathrm{~s}) \rightarrow 3 \mathrm{SiO}(\mathrm{g})+\mathrm{CO}(\mathrm{g}) \\
\mathrm{SiC}(\mathrm{s})+\mathrm{O}_{2}(\mathrm{~g}) \rightarrow \mathrm{SiO}(\mathrm{g})+\mathrm{CO}(\mathrm{g})
\end{gathered}
$$

Active oxidation of SiC occurs only at oxygen pressures lower than $\sim 3 \cdot 10^{-4}$ atm at $1400^{\circ} \mathrm{C}$.

As seen from Equations (2-3) surface oxidation of silicon carbide in this conditions leads to production flow of both as Carbon and Silicon vacancies from the surface into the bulk of the crystal (May be mostly of carbon vacancies). Obviously, the vacancy concentration in this case can be much higher as compared with the introduction of vacancies by irradiation.

\subsection{Distribution of Boron Impurity in Samples after Low-Temperature Diffusion}

The diffusion of Boron in $\mathrm{SiC}$ was performed in nonequilibrium conditions in the flow of vacancies from the surface into volume of crystal using the method described in [1,2]. In this low-temperature diffusion technique, a thin film of borosilicate glass is created on the surface of a silicon carbide sample. Then sample is annealed in the air. Temperature of diffusion was different between $1150^{\circ} \mathrm{C}$ and $1300^{\circ} \mathrm{C}$.

The distribution of $\mathrm{B}$ in the $\mathrm{SiC} / \mathrm{SiC}$ samples was measured by spreading current method. In this method, the samples were polished by diamond paste at a gradient of 1 - 3 degrees to the surface of the SiC crystal. Then the distribution of specific resistance along the surface of the $\mathrm{SiC}$ film was measured to obtain the distribution profile of boron, $N_{B}(x)$.

Diffusion in crystals of silicon carbide of various polytypes was carried out as well. Since diffusion is stimulated by defects the inhomogeneity of the distribution of impurities and defects in the crystals play an important role. As a result, the surface and depth distribution of impurity in p-area is nonuniform. Figure 1 shows the distribution of the impurity measured in different points of the 3C-SiC crystal and distribution of Boron in $4 \mathrm{H}-\mathrm{SiC}$.

Estimates have shown that for bulk crystals of silicon carbide activation energy of diffusion $\mathrm{E}_{\mathrm{a}} \sim 0.9-1.2 \mathrm{eV}$ as was determined in experiments with $\mathrm{SiC} / \mathrm{SiC}$ heterostructures in [4].

\subsection{Some Remarks on Possible Mechanism of Low-Temperature Diffusion of Boron}

In our previous work [4], based on an analysis of literature on diffusion mechanisms in SiC [7-11] has been assumed that the accelerated diffusion takes place via mobile $\left(B_{\mathrm{c}}-V_{\mathrm{c}}\right)$ associates.

However, according to expressions $(2,3)$ silicon vacancy are also formed on the surface of the crystal. Thus it can be assumed that the diffusion of impurities goes via $\mathrm{Si}$ and $\mathrm{C}$ vacancies at different rates and as described in [8] with a different solubility in Si and C-sublattices.

To test this hypothesis in samples without the borosilicate glass layer a boron diffusion was performed in vacuum with low oxygen pressure (as in work [6]). After diffusion at $1200^{\circ} \mathrm{C}$ in $\mathrm{SiC}$ crystal the p-type layer was created. Thus, according to expressions $(2,3)$ a flow of $V_{c}$ and $V_{\mathrm{Si}}$ vacancies is creates and the stimulated diffusion occurs. However, in the obtained samples p-region was a 


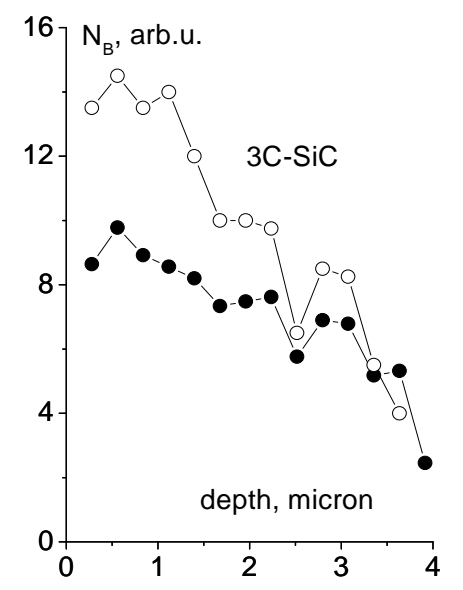

(a)

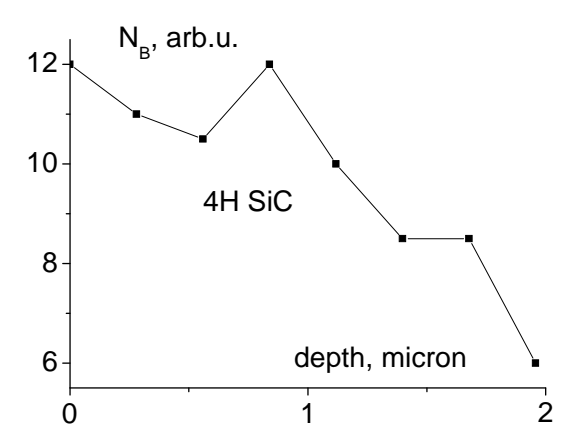

(b)

Figure 1. (a) Distribution of $N_{B}$ in different points of p-area of $3 \mathrm{C} \mathrm{SiC}$ after diffusion in nonequilibrium conditions at $1200^{\circ} \mathrm{C}$; (b) Distribution of $N_{B}$ versus $x$ after diffusion in $4 \mathrm{H}$ $\mathrm{SiC}$ crystals in nonequilibrium conditions at $1200^{\circ} \mathrm{C}$.

very inhomogeneous, most of the p-n junctions has almost linear characteristic. Detailed results on diffusion of $\mathrm{SiC}$ in vacuum will be published in the next article after some additional experiments.

Let us return to our experiments. Since the diffusion occurs at a constant generation of vacancies at the crystal surface installs a quasi-steady state in which the vacancy concentration has maximum value at the surface and tends to zero at some depth. The diffusion of impurity occurs only in the area saturated by nonequilibrium vacancies. So the impurity distribution is determined by the distribution of vacancies. Obviously, in this case, the diffusion depth weakly depends on the diffusion time.

Consider the distribution of vacancies at generation of $V_{\mathrm{C}}$ and $V_{\mathrm{Si}}$ on the surface with a constant rates (It was assumed that the mechanisms of diffusion in all polytypes of silicon carbide are similar). Diffusion equations can be write as:

$$
\frac{\partial V_{\mathrm{C}}}{\partial t}=D_{V_{\mathrm{C}}} \frac{\partial^{2} V_{\mathrm{C}}}{\partial x^{2}}-\frac{V_{\mathrm{C}}}{\tau_{V_{\mathrm{C}}}}-\left(V_{\mathrm{SiC}}\right)+G_{V_{\text {SiC }}}
$$

$$
\begin{aligned}
& \frac{\partial V_{\mathrm{Si}}}{\partial t}=D_{V_{\mathrm{Si}}} \frac{\partial^{2} V_{\mathrm{Si}}}{\partial x^{2}}-\frac{V_{\mathrm{Si}}}{\tau_{V_{\mathrm{Si}}}}-\left(V_{\mathrm{SiC}}\right)+G_{V_{\mathrm{SiC}}} \\
& \frac{\partial V_{\mathrm{SiC}}}{\partial t}=D_{2} \frac{\partial^{2} V_{2}}{\partial x^{2}}-\frac{V_{\mathrm{SiC}}}{\tau_{\mathrm{V}_{\mathrm{SiC}}}}+\left(V_{\mathrm{SiC}}\right)-G_{V_{\mathrm{SiC}}}
\end{aligned}
$$

Here, $V_{\mathrm{C}}, V_{\mathrm{Si}} V_{\mathrm{SiC}}$ concentration of carbon and silicon vacancies and $\left[V_{\mathrm{C}} V_{\mathrm{Si}}\right]$ divacancies; $D$ diffusion coefficients; $\left(V_{\mathrm{SiC}}\right)$ - term accounts for decrease in $V_{\mathrm{C}}, V_{\mathrm{si}}$ of the formation of divacancies $\left[V_{\mathrm{si}} V_{\mathrm{c}}\right]$; $G$-secondary generation of vacancies due to the disintegration of $V_{\mathrm{SiC}}$ divacancies. Additionally to main reactions $\left(V_{\mathrm{C}}+V_{\mathrm{Si}} \rightarrow V_{\mathrm{SiC}}\right.$ and $V_{\mathrm{SiC}} \rightarrow V_{\mathrm{C}}+V_{\mathrm{Si}}$ ) there are following reactions of annihilation of vacancies: interaction with impurities and the formation of impurity-vacancy complexes, annihilation reactions with dislocations, microcracks and other point and 2D, 3D defects of SiC crystal. These reactions are varied and their consideration is very complicated.

In the work [12] considering the radiation defect formation in SiGe to account for different mechanisms of annihilation of point defects (except the main reaction) introduce parameters $\tau$ having the dimension of time "effective lifetime". In our case, as all above mentioned reactions leads to annihilation of vacancies we also introduce the effective parameters $\tau_{V_{\mathrm{Si}, \mathrm{C}}}$. These parameters describe the interaction with defects of crystal in diffusion area. Parameters $\tau_{V_{\mathrm{Si}, \mathrm{C}}}$ can vary widely, depend sharply on mechanical (cutting, polishing) and thermal treatments, which performed on a sample.

Assuming that the formation of divacancies is proportional to the product of vacancy concentration $\alpha V_{\mathrm{C}} V_{\mathrm{Si}}$, and secondary generation is proportional to the concentration of divacancies $\beta V_{\mathrm{SiC}}$ :

$$
\begin{aligned}
& \frac{\partial V_{\mathrm{C}}}{\partial t}=D_{V_{\mathrm{C}}} \frac{\partial^{2} V_{\mathrm{C}}}{\partial x^{2}}-\frac{V_{\mathrm{C}}}{\tau_{V_{\mathrm{C}}}}-\alpha V_{\mathrm{C}} V_{\mathrm{Si}}+\beta V_{\mathrm{SiC}} \\
& \frac{\partial V_{\mathrm{Si}}}{\partial t}=D_{V_{\mathrm{Si}}} \frac{\partial^{2} V_{\mathrm{Si}}}{\partial x^{2}}-\frac{V_{\mathrm{Si}}}{\tau_{V_{\mathrm{Si}}}}-\alpha V_{\mathrm{C}} V_{\mathrm{Si}}+\beta V_{\mathrm{SiC}}
\end{aligned}
$$

In the steady state $\left(\frac{\partial V_{\mathrm{C}}}{\partial t}=0, \frac{\partial V_{\mathrm{Si}}}{\partial t}=0, \frac{\partial V_{\mathrm{SiC}}}{\partial t}=0\right)$

$$
\begin{gathered}
D_{V_{\mathrm{C}}} \frac{\partial^{2} V_{\mathrm{C}}}{\partial x^{2}}-\frac{V_{\mathrm{C}}}{\tau_{V_{\mathrm{C}}}}-\alpha V_{\mathrm{C}} V_{\mathrm{Si}}+\beta V_{\mathrm{SiC}}=0 \\
D_{V_{\mathrm{Si}}} \frac{\partial^{2} V_{\mathrm{Si}}}{\partial x^{2}}-\frac{V_{\mathrm{Si}}}{\tau_{V_{\mathrm{Si}}}}-\alpha V_{\mathrm{C}} V_{\mathrm{Si}}+\beta V_{\mathrm{SiC}}=0
\end{gathered}
$$

Assuming that in the near-surface area of sample the main factor is the formation of divacancies obtain the following solution for distribution of $V_{\mathrm{Si}}$ and $V_{\mathrm{C}}$ : 


$$
\begin{gathered}
V_{\mathrm{Si}}=\frac{3 D_{V_{\mathrm{C}}}}{\left(\sqrt{8 \alpha} x+C_{\mathrm{C}}\right)^{2}} \\
V_{\mathrm{C}}=\frac{3 D_{V_{\mathrm{Si}}}}{\left(\sqrt{8 \alpha} x+C_{\mathrm{Si}}\right)^{2}}
\end{gathered}
$$

Integration constants $C_{\mathrm{C}}$ and $C_{\mathrm{Si}}$ can be found from the initial conditions: the generation rate of vacancies on the surface is constant (the derivative at zero is equal $-G_{\mathrm{C}}$, $\left.-G_{\mathrm{Si}}\right)$

The maximum concentration of vacancies at the surface is proportional to $G^{2 / 3}$ :

$$
\begin{gathered}
V_{\mathrm{C}}(0)=\frac{3 D_{\mathrm{V}_{\mathrm{Si}}}{ }^{1 / 3} G_{\mathrm{C}}{ }^{2 / 3}}{(6 \sqrt{8 \alpha})^{2 / 3}} \\
V_{\mathrm{Si}}(0)=\frac{3{V_{V_{\mathrm{C}}}}^{1 / 3} G_{\mathrm{Si}}{ }^{2 / 3}}{(6 \sqrt{8 \alpha})^{2 / 3}}
\end{gathered}
$$

The analysis shows that the influence of other mechanisms of annihilation of vacancies (taking into account via $\tau$ effective lifetime of the vacancies) leads to a change in the shape of the distribution of vacancies. But maximal value $V_{\mathrm{c}}(\mathrm{o})$ and $V_{\mathrm{si}}(0)$ on the surface almost not changes and depends only from $G$. If the defect distribution is nonuniform on depth (distribution $\tau$ also) the distribution of impurities becomes irregular (not smooth) as in Figure 1.

\subsection{UV Etching of SiC}

As can be seen from Figure 1, the distribution of boron impurities in various locations of the crystal is different. Amplitude of boron concentration in distribution along surface is changes. Measurement of the distribution of specific resistance along the crystal surface shows that the p-region is inhomogeneous. As a result, only 25\% $30 \%$ of produced $\mathrm{p}-\mathrm{n}$ structures have a nonlinear I-V characteristics, reverse breakdown voltage is low (up to 5Volt). Thus, the value of $\tau$ inhomogeneously distributed in diffusion area of samples.

As follows from our simplified mechanism the diffusion of impurities strongly modulated by defects in the surface-damaged layer of SiC samples. In conventional semiconductors the depth of surface-damaged layer reaches a 5 - 6 microns and depends from method of technological processing. In this regard, it is important to develop a method of etching silicon carbide is not only to clean the surface, but also to remove the surfacedamaged layer.

Silicon carbide is a chemically stable compound. It is not etched by conventional acids. They are used just for surface cleaning of SiC. And when it is necessary to removing of $\mathrm{SiC}$ layer an ion etching or special types of etchants are used. For example, the melt of $\mathrm{KOH}$ at temperatures $500^{\circ} \mathrm{C}-900^{\circ} \mathrm{C}[13,14]$ used for etching for the manufacture of $\mathrm{SiC}$ devices. An anodic etching at room temperature in a solution $\left(\mathrm{HF}+\mathrm{C}_{2} \mathrm{H}_{5} \mathrm{OH}+\mathrm{HNO}_{3}\right)$ at the current density of $20-120 \mathrm{~mA} / \mathrm{cm}^{2}$ was used for the manufacture of porous silicon carbide $[15,16]$.

Etching of silicon carbide by liquid metals, for example, Manganese at $1200^{\circ} \mathrm{C}$, was carried out in [17] and by liquid Aluminum [18].

As it is evident from the literature, this process for silicon carbide is very time-consuming and complicated, leading to increased cost of $\mathrm{SiC}$ devices. Widely used now methods of surface sputtering are introduced defects into a thin surface layer, which in our method of diffusion plays a crucial role. That is why it is important to develop a new method of etching, which does not introduce defects and provides a smooth surface.

In this section, the etching of silicon carbide in a $\mathrm{KOH}$ solution stimulated by electrical current and UV radiation at room temperature was investigated. Our objective was to obtain a mirror-smooth surface of silicon carbide without the use of high-temperature processes.

Well known it is very difficult to make selective etching using the high-temperature processes. That is why we tried to do etching of silicon carbide in aqueous $\mathrm{KOH}$ (30\% - 50\%) at room temperature, stimulating by electrical current and UV radiation.

Since the process occurs at room temperature in a relatively inactive medium for selective etching as a mask could be used ordinary chemically resistant lacquer or even masking tape.

Well known [19] at the border of semiconductorelectrolyte forms a double barrier layer. And application of the electrical current can make a significant impact in the electrolytic etching mechanism [15]. The light if it is generate a surface holes is also can be used for stimulation of etching [20]. As is known, [21] for etching of semiconductors can play an important role excitation of surface states, when a surface holes or two-hole state are created. Time of localization of the hole in the bulk of crystal is $\sim 10^{-15}$ seconds and the bonds in crystal do not manage to break off. On the surface time of localization of holes considerably higher $\sim 10^{-14-13}$ sec. And stimulation by light quanta with energy above the energy bandgap leads to formation surface two-hole states, resulting to creation of a weak and dangling bonds on the surface. Thus, ultraviolet light (UV) can induce etching of silicon carbide.

Initially in our experiments the etching was carried out at room temperature without active mixing of the solution. For n-type crystals at $300 \mathrm{~K}$ a very slow etching of 
about 0.05 - $0.1 \mathrm{micron} /$ hour is observed. Rate of etching of $\mathrm{SiC}$ crystals with high-resistance p-layer is also slow. Etched surface is uneven, has a matte color.

Experiments have shown that stimulation by electrical current does not give positive result: the surface of the crystal is not uniform and not smooth. Etching highlights areas with a high resistivity or with non-uniform thickness of the oxide layer. The etching rate reaches $1 \mathrm{mi}-$ cron/hour.

Further experiments showed that under UV illumination of the etching rate also reaches 1 - 2 micron/h (which is 10 times higher than without light stimulation). UV stimulated etching with active mixing of solution allowed to obtain a sufficiently smooth surface of SiC crystal.

The Figure 2 shows photographs of surface of $4 \mathrm{H} \mathrm{SiC}$ with 3D defect taken by interference microscope: (a)the surface of $4 \mathrm{H} \mathrm{SiC}$ crystal before etching; (b)-after etching during 5 - 6 hours (before the diffusion process); (c) - after secondary etching during 5 hours for formation of mesa-structure. As can be seen from the figures, the surface remains smooth, despite to double etching and region with 3D defect becomes much smoother: According evaluation on the base of Figure 2(c) after second etching the roughness height is $\sim 0.4-0.6$ micron.

\subsection{Influence of Thermal Annealing on IV Characteristics of p-n SiC Junctions Prepared by Low Temperature Diffusion}

Since the low temperature diffusion is performed in a flow of carbon vacancies, the obtained p-SiC layers contain defects. Applicability of this technology is subject to availability of the efficient ways of removing of defects in the structures.

In a previous article [4] it was shown that thermal annealing in vacuum (at $500^{\circ} \mathrm{C}, 700^{\circ} \mathrm{C}, 900^{\circ} \mathrm{C}$ during 10 minutes) allows to reduce concentration of defects in SiC/SiC structures. The following are comparative data on the effect of annealing on the I-V characteristics of p-n junctions prepared on bulk samples with conventional SiC chemical treatment, without UV etchinggroup 1) and crystals in which the surface-damaged layer was removed (with UV etching-group 2).

Group 1: For crystals from group1 - most of p-n junctions (up to 75\%) have almost linear I-V characteristics (as well as in experiments on $\mathrm{SiC} / \mathrm{SiC}$ and $\mathrm{SiC} / \mathrm{Si}$ structures [4]). In the samples with non-linear I-V the breakdown voltage was low (up to 5 - 6 Volt), with a coefficient of nonlinearity $k=4-10$ at 2 volts. (Coefficient of nonlinearity $\mathrm{k}$ is the ratio of the forward and reverse currents for structure). The thermal annealing in vacuum at $500^{\circ} \mathrm{C}, 700^{\circ} \mathrm{C}$ and $900^{\circ} \mathrm{C}$ lead to worsening of quality of p-n junctions and for most samples the IV becomes linear (Figure 3). In some samples with a linear I-V the nonlinearity is appeared after annealing, but coefficient of nonlinearity k was very low 2 - 4 .

Thus, after low temperature diffusion in samples with surface-damaged layer the distribution of impurities is very nonuniform. This distribution is changed under thermal annealing $\left(\mathrm{T}=500^{\circ} \mathrm{C}-900^{\circ} \mathrm{C}\right)$. As a result, character of IV is also changing. However, the quality and uniformity of p-type regions is so low that annealing practically does not improve situation.

Group 2: After removing of surface-damaged layer by UV etching the low-temperature diffusion of boron in silicon carbide of various polytypes was conducted. Diameter of p-area was 2 - $3 \mathrm{~mm}$.

Measurement of the distribution along the surface of the crystals showed the homogeneity of the p-region has become much better: most of structures have nonlinear IV characteristics (more 80\%), the reverse breakdown voltage increased up to 30 - 40 Volt, the coefficient of nonlinearity k was $10^{3}-10^{6}$ at 2 Volt. (Figure 4). Annealing at $500^{\circ} \mathrm{C}-900^{\circ} \mathrm{C}$ not change IV characteristics. Remind that only $20 \%$ - $30 \%$ of junctions were a nonlinear and reverse breakdown voltage was up to 5 Volt. As the average flatness of $\mathrm{SiC}$ surface not changed the shape

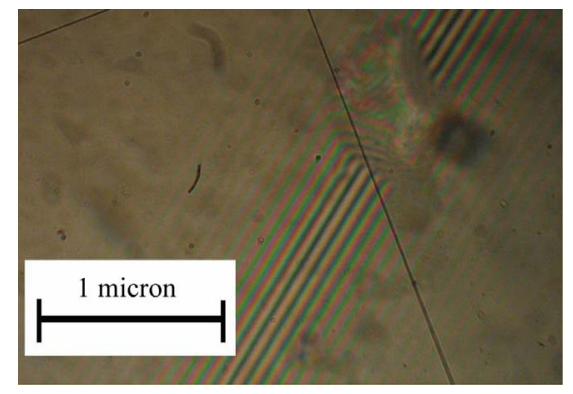

(a)

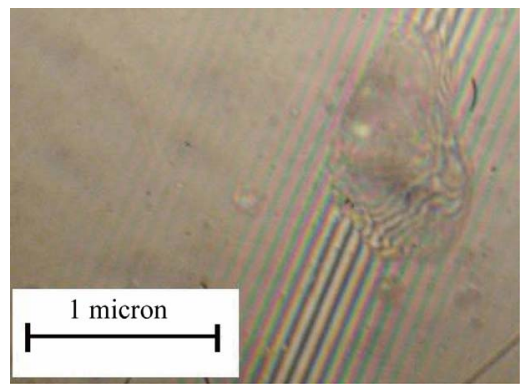

(b)

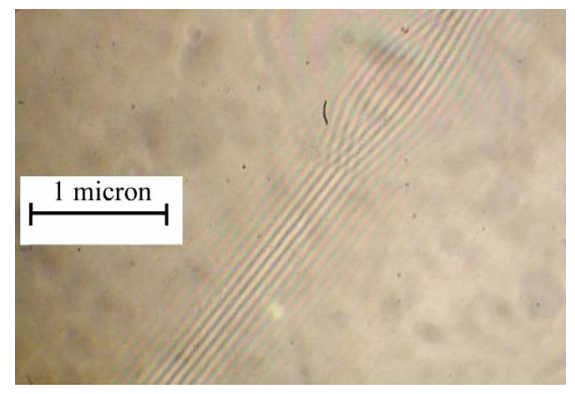

(c)

Figure 2. Photo of surface of $4 \mathrm{H} \mathrm{SiC}$ with 3D defect taken by interference microscope: (a) - the surface of SiC crystal before etching; (b) - after etching during 5 - 6 hours (before the diffusion process); (c)—after secondary etching during 5 hours for formation of mesa-structure. 

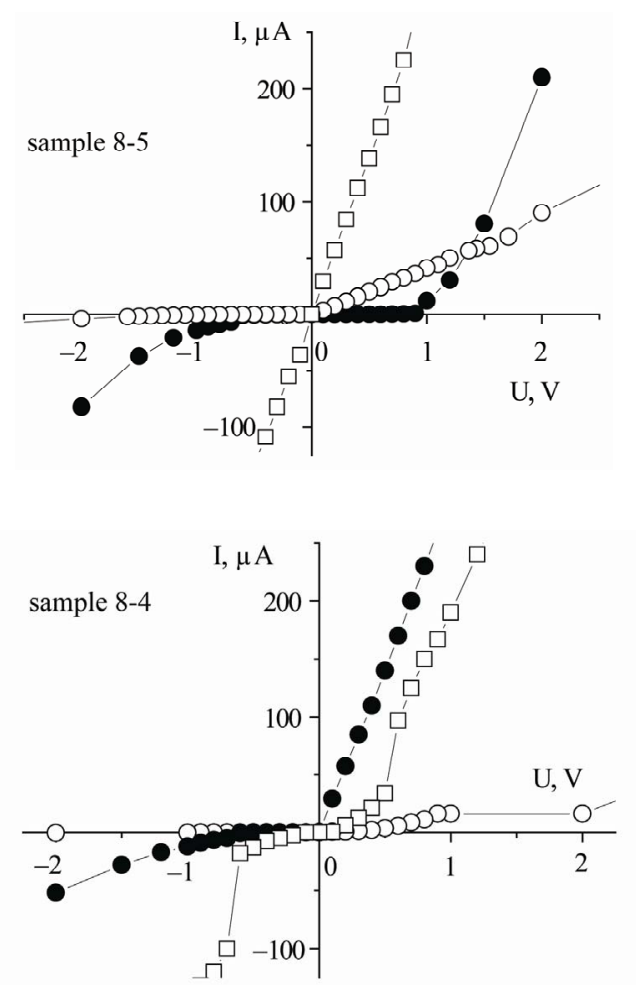

Figure 3. Influence of annealing on IV-characteristics of p-n 4H SiC sample from group 1: $\bigcirc$ IV after diffusion at $1300^{\circ} \mathrm{C}$; • IV after annealing at $500^{\circ} \mathrm{C}$; $\square \mathrm{IV}$ after annealing at $700^{\circ} \mathrm{C}$.

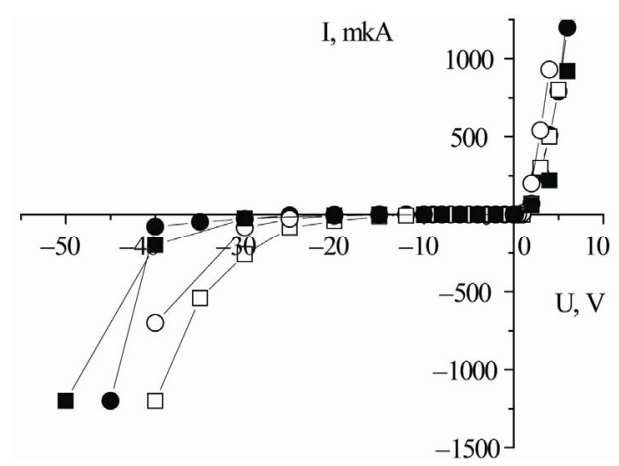

Figure 4. Influence of annealing on IV-characteristics of p-n 4H SiC sample from group 2: $\odot$ IV after diffusion at $1300^{\circ} \mathrm{C}$; - IV after annealing at $500^{\circ} \mathrm{C}$; $\square$ IV after annealing at $700^{\circ} \mathrm{C}$; $-\mathrm{IV}$ after annealing at $900^{\circ} \mathrm{C}$.

of $\mathrm{p}-\mathrm{n}$ border of samples from group 1 and 2 the same. Apparently, improving of IV characteristics is connected with the removal of the surface-damaged layer containing increased concentration of defects.

\section{Conclusions}

Thus the low temperature diffusion of Boron in bulk SiC crystals is investigated, the simplified model of diffusion is presented, the method of UV stimulated etching by aqueous solution of $\mathrm{KOH}$ is proposed and some experimental data on influence of defects on quality of prepared p-n junctions are presented.

\section{REFERENCES}

[1] I. G. Atabaev, T. M. Saliev and E. N. Bakhranov, "Method of Diffusion of Boron in Silicon Carbide," Patent of Uzbekistan IDP 05199.

[2] C. C. Tin, et al., "Low Temperature Impurity Doping of Silicone Carbide,” US Patent Application Publication, Pub No: US 2009/0039469 A1, February 2009.

[3] C.-C. Tin, T. Saliev, B. Atabaev, et al., "Oxide Film Assisted Dopant Diffusion in Silicon Carbide,” Thin Solid Films, Vol. 518, No. 24, October 2010, pp. e118-e120. doi:10.1016/j.tsf.2010.03.107

[4] I. G. Atabaev, C.-C. Tin, T. Saliev, B. Atabaev, et al., "Nonequilibrium Diffusion of Boron in SiC at Low Temperatures,” Materials Sciences and Applications, Vol. 1, 2010, pp. 53-58.

[5] A. Y. Kuznetsov, M. Janson, A. Hallen, B. G. Svensson and A. N. Larsen, "Boron Diffusion in Si and SiC during $2.5 \mathrm{MeV}$ Proton Irradiation at $500-850^{\circ} \mathrm{C}$,” Nuclear Instruments and Methods in Physics Research Section B: Beam Interactions with Materials and Atoms, Vol. 148, No. 1-4, 1999, pp. 279-283. doi:10.1016/S0168-583X(98)00740-X

[6] S. C. Singhal, "Oxidation Kinetics of Hot Pressed Silicon Carbide,” Journal of Material Science, Vol. 11, No. 7, 1976, pp. 1246-1253.

[7] K. Rüschenschmidt, H. Bracht, M. Laube, N. A. Stolwijk and G. Pensl, "Diffusion of Boron in Silicon Carbide," Physica B: Condensed Matter, Vol. 308-310, 2001, pp. 734-737.

[8] Y. Gao, S. I. Soloviev and T. S. Sudarshan, "Investigation of Boron Diffusion in 6H-SiC," Applied Physics Letters, Vol. 83, No. 5, August 2003, pp. 905-907.

[9] I. Girka and E. N. Mokhov, "Vacancy Defects in Silicon Carbide," Physics of the Solid State, Vol. 37, No. 11, 1995, pp. 1855-1858.

[10] K. Mochizuki, H. Shimizu and N. Yokoyama, "DualSublattice Modeling and Semi-Atomistic Simulation of Boron Diffusion in 4H-Silicon Carbide," Japanese Journal of Applied Physics, Vol. 48, 2009, p. 031205 (6 Pages).

[11] P. G. Baranov, I. V. Il'in and E. N. Mokhov, "Electron Paramagnetic Resonance of Deep Boron Acceptors in 4H-SiC and 3C-SiC Crystals," Physics of the Solid State, Vol. 40, No. 1, 1998, pp. 31-34. doi:10.1134/1.1130226

[12] I. G. Atabaev, M. S. Saidov, L. I. Khirunenko, V. I. Shakhovcov, V. K. Shinkarenko, L. I. Shpinar and A. Yusupov. "Mechanism of Defect Formation in $\mathrm{Si}_{\mathrm{x}} \mathrm{Ge}_{1-\mathrm{x}}$ Alloys Irradiated with Electrons,” Fiz. Tekh. Poluprovodn., Vol. 21, 1987, pp. 570-573.

[13] M. Katsuno, N. Ohtani, J. Takahashi, H. Yashiro and M. Kanaya, "Mechanism of Molten KOH Etching of SiC 
Single Crystals: Comparative Study with Thermal Oxidation,” Japanese Journal of Applied Physics, Vol. 38, No. 8, 1999, pp. 4661-4665. doi:10.1143/JJAP.38.4661

[14] S. A. Sakwe, R. Müller and P. J. Wellmann, “Optimization of $\mathrm{KOH}$ Etching Parameters for Quantitative Defect Recognition in n- and p-Type Doped SiC," Journal of Crystal Growth, Vol. 289, No. 2, April 2006, pp. 520-526. doi:10.1016/j.jcrysgro.2005.11.096

[15] V. F. Agekyan, A. A. Lebedev and Y. A. Stepanov, "Photoluminescence of Anodized Silicon Carbide," Fiz. Tehn. Poluprovodnikov (Russia), Vol. 31, No. 2, 1997, pp. 251-253.

[16] V. Petrova-Kocha, O. Sreselib, G. Polisskia, D. Kovalevb, T. Muschika and F. Kocha. "Luminescence Enhancement by Electrochemical Etching of $\mathrm{SiC}(6 \mathrm{H})$," Thin Solid Films, Vol. 255, No. 1-2, January 1995, pp. 107-110.

[17] Kh. Shamuratov, T. Saliev, et al., "Influence of Manganese on Growth and Properties of SiC," Journal of Uzbek
Physics, No. 2, 1997, pp. 26-31.

[18] J. C. Viala, F. Bosselet, V. Laurent and Y. Lepetitcorps, "Mechanism and Kinetics of the Chemical Interaction between Liquid Aluminium and Silicon-Carbide Single Crystals,” Journal of Materials Science, Vol. 28, No. 19, 1993, pp. 5301-5312. doi:10.1007/BF00570081

[19] J van de Lagemaat, D. Vanmaekelbergh and J. J. Kelly. "Photoelectrochemical Characterization of 6H-SiC," Journal of Applied Physics, Vol. 83, No. 11, 1998, pp. 6089-6095.

[20] M. S. Ferdous, X. Y. Sun, X. Wang, M. N. Fairchild and S. D. Hersee. "Photoelectrochemical Etching Measurement of Defect Density in GaN Grown by Nanoheteroepitaxy,” Journal of Applied Physics, Vol. 99, No. 9, 2006, p. 096105. doi:10.1063/1.2197059

[21] B. G. Atabaev, "Surface-Exciton Mechanism of Potential Sputtering of Ionic and Covalent Crystal by Multicharged Ions,” Surface Investigation, Vol. 4, 2009, pp. 1-4. 